\title{
Association between Lipid Accumulation Product and Hirsutism in Patients with Polycystic Ovary Syndrome
}

\section{Associação entre lipid accumulation product (LAP) $e$ hirsutismo na síndrome do ovário policístico}

\author{
Ana Lúcia Cândido ${ }^{4}$

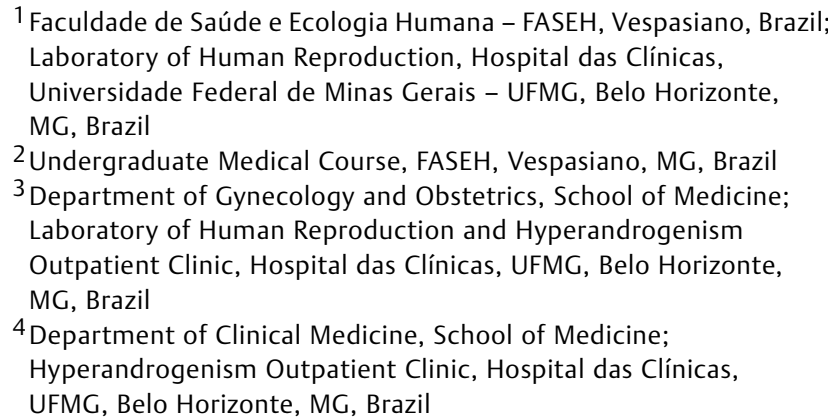

Flávia Ribeiro de Oliveira ${ }^{1}$ Mariana Bicalho Rezende ${ }^{2}$ Nícolas Figueiredo Faria ${ }^{2}$

Tomás Ribeiro Gonçalves Dias ${ }^{2}$ Walter Carlos Santos de Oliveira ${ }^{2}$ Ana Luiza Lunardi Rocha ${ }^{3}$

Address for correspondence Flávia Ribeiro de Oliveira, MD, MSc, School of Health and Human Ecology and the Hyperandrogenism Outpatient Clinic, Hospital das Clínicas, Universidade Federal de Minas Gerais, Rua Hortênsia 698/402, Bairro Esplanada, Belo Horizonte 30280-250, MG, Brazil (e-mail: flaviagob@bol.com.br).

Rev Bras Ginec Obst 2016;38:71-76.

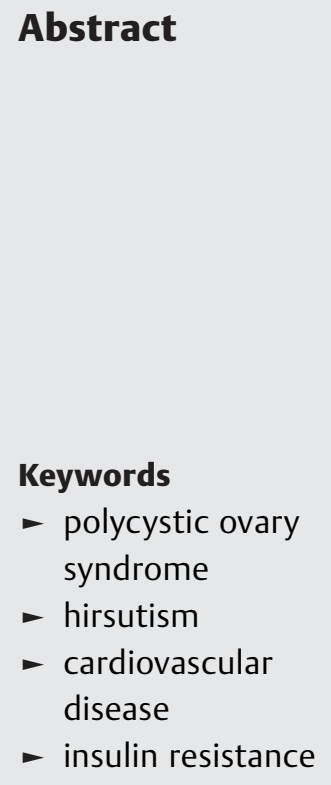

Objective Polycystic ovary syndrome (PCOS) is the most common endocrine metabolic disorder in women between menarche and menopause. Clinical hyperandrogenism is the most important diagnostic criterion of the syndrome, which manifests as hirsutism in $70 \%$ of cases. Hirsute carriers of PCOS have high cardiovascular risk. Lipid accumulation product (LAP) is an index for the evaluation of lipid accumulation in adults and the prediction of cardiovascular risk. The aim of this study was to evaluate the association between LAP and hirsutism in women with PCOS.

Methods This was a cross-sectional observational study of a secondary database, which included 263 patients who had visited the Hyperandrogenism Outpatient Clinic from November 2009 to July 2014. The exclusion criteria were patients without Ferriman-Gallwey index (FGI) and/or LAP data. We used the Rotterdam criteria for the diagnosis of PCOS. All patients underwent medical assessment followed by measurement and recording of anthropometric data and the laboratory tests for measurement of the following: thyroid-stimulating hormone, follicle-stimulating hormone, prolactin, total testosterone, sex hormone binding globulin, 17- $\alpha$-hydroxyprogesterone (follicular phase), glycohemoglobin A1c, and basal insulin. In addition, the subjects underwent lipid profiling and oral glucose tolerance tests. Other received

June 30,2015

accepted

November 25, 2015

published online

$\mathrm{xxxx}$
DOI http://dx.doi.org/

10.1055/s-0036-1571423. ISSN 0100-7203.
Copyright $@ 2016$ by Thieme Publicações License terms

Ltda, Rio de Janeiro, Brazil 


\section{Resumo}

\section{Palavras-chave}

- síndrome dos ovários policísticos

- hirsutismo

- doença cardiovascular

- resistência à insulina laboratory measurements were determined according to clinical criteria. LAP and the homeostatic model assessment index (HOMA-IR) were calculated using the data obtained. We divided patients into two groups: the PCOS group with normal LAP $(<34.5)$ and the PCOS group with altered LAP (>34.5) to compare the occurrence of hirsutism. For statistical analysis, we used SPSS Statistics for Windows ${ }^{\circledR}$ and Microsoft Excel programs, with descriptive (frequencies, percentages, means, and standard deviations) and comparative analyses (Student's $t$-test and Chi-square test). We considered relations significant when the $\mathrm{p}$-value was $\leq 0.05$.

Results LAP was high in most patients $(n=177 ; 67.3 \%)$ and the FGI indicated that $58.5 \%$ of the patients $(n=154)$ had hirsutism. The analysis by LAP quartiles showed a positive correlation $(p=0.04)$ among patients with a high $\mathrm{FGl}$ and an upper quartile LAP ( $>79.5$ ) when compared with those with LAP $<29.0$ (lower quartile).

Conclusion This study demonstrated an association between high LAP and hirsutism. The FGI could represent a simple and low-cost tool to infer an increased cardiovascular risk in women with PCOS.

Objetivo A síndrome dos ovários policísticos (SOP) é o distúrbio endócrino mais comum em mulheres entre a menarca e a menopausa. O hiperandrogenismo clínico é o critério diagnóstico mais importante da síndrome, que se manifesta como hirsutismo em $70 \%$ dos casos. Portadores de SOP hirsutas têm elevado risco cardiovascular. O Lipid accumulation product (LAP) é um índice para a avaliação da acumulação de lípidos nos adultos e é um preditor de risco cardiovascular. O objetivo deste estudo é avaliar a associação entre LAP e hirsutismo em portadoras da SOP.

Métodos Estudo observacional transversal de banco de dados secundário, que incluiu 263 pacientes do Ambulatório de Hiperandrogenismo no período de novembro de 2009 a julho de 2014. Foram excluídas pacientes sem o índice de Ferriman-Gallwey e/ ou LAP. Foram utilizados como critérios diagnósticos da SOP os critérios de Rotterdam. Todas as pacientes foram submetidas à avaliação médica seguida da aferição e registro dos dados antropométricos e a realização dos seguintes exames laboratoriais: hormônio estimulante da tireoide (TSH), hormônio folículo estimulante (FSH), prolactina (PRL), Testosterona total, globulina ligadora dos hormônios sexuais (SHBG), 17- $\alpha-$ hidroxiprogesterona, (fase folicular), perfil lipídico, teste oral de tolerância à glicose, glico-hemoglobina a1C, insulina basal. Outras dosagens laboratoriais foram determinadas à critério clínico. O LAP e o HOMA-IR (homeostatic model assessment) foram calculados com os dados obtidos. As pacientes foram divididas em dois grupos: grupo das portadoras de SOP com LAP normal (LAp $<34,5)$ e grupo das portadoras de SOP com LAP alterado (LAP $>34,5$ ) para as comparações do hirsutismo. Para a análise estatística, foram utilizados os programas SPSS Statistics for Windows ${ }^{\circ}$ e Microsoft Excel ${ }^{\circledR}$, sendo feitas análises descritivas (frequências, percentuais, médias, desviospadrão) e comparativas (t-Student e qui-quadrado). Foram consideradas relações significativas quando p-valor foi menor ou igual a 0,05 .

Resultados OLAP foi elevado na maioria das pacientes $(n=177 ; 67,3 \%)$ e o índice de Ferriman-Gallwey (IF) demonstrou que $58,5 \%$ das pacientes $(n=154)$ eram hirsutas. A análise por quartis de LAP, demonstrou correlação positiva $(p=0,04)$ entre pacientes com IF elevado e LAP no quartil superior $(>79,5)$ quando comparadas àquelas com LAP menor que 29,0 (quartil inferior).

Conclusão O estudo demonstrou associação do LAP elevado e hirsutismo. O escore de Ferriman-Gallwey poderia representar uma ferramenta simples e de baixo custo para inferir risco cardiovascular aumentado em portadoras da síndrome. 


\section{Introduction}

Polycystic ovary syndrome (PCOS) is the most common endocrine metabolic disorder in women between menarche and menopause. It may reach a prevalence $>18 \%$ according to the Rotterdam classification criterion. ${ }^{1-3}$ This condition can manifest in four different phenotypes: classical phenotype (anovulation or oligo-ovulation with irregular menses, clinical and/or laboratory hyperandrogenism, and polycystic ovaries on ultrasound, US); ovulatory phenotype (hyperandrogenism and polycystic ovaries on US); nonhyperandrogenic phenotype (anovulation or oligo-ovulation and polycystic ovary on US); and the phenotype that includes hyperandrogenism and anovulation or oligo-ovulation, but with no changes on US., ${ }^{2,4}$

Clinical hyperandrogenism is an important diagnostic criterion of the syndrome, manifested as hirsutism (70\%), acne (20\%), and androgenic alopecia (5\%). Hirsutism is evaluated by using the modified Ferriman-Gallwey index (FGI). The FGI is considered a good instrument for evaluating hirsutism, even considering ethnic differences among patients. $^{5-7}$ In adult women, hirsutism, acne, and alopecia are good substitutes of biochemical hyperandrogenism and should be considered as indicators of excessive androgen production. During adolescence, only hirsutism should be considered as a surrogate of biochemical hyperandrogenism, as acne is very common and often reversible, and alopecia is uncommon and generally has other causes. ${ }^{5}$ In this study, we considered only hirsutism as an indicator of hyperandrogenism.

Hirsute carriers of PCOS have a 3-fold risk of developing metabolic syndrome (MS) compared with those without hirsutism. ${ }^{8,9}$ MS occurs in $\sim 43 \%$ of PCOS carriers, causing up to a 7-fold elevation of cardiovascular risk. ${ }^{8-10}$

Lipid accumulation product (LAP) is an index for the evaluation of lipid accumulation in adults and the prediction of cardiovascular risk. This index was proposed for the first time in 2005 in an epidemiological study with the database of the National Health and Nutrition Examination Survey (NHANES III). ${ }^{11}$ In that study, LAP showed better accuracy than body mass index (BMI) in the evaluation of cardiovascular risk in adult Americans. This index reflects lipid accumulation in adults in a simple way, and may be calculated by using the formula $\{\mathrm{LAP}=[\mathrm{AC}(\mathrm{cm})-58] \times \mathrm{TGL}$ $(\mathrm{mmol} / \mathrm{L})\},{ }^{11}$ where $\mathrm{AC}$ is the abdominal circumference and TGL is the level of fasting triglycerides. In addition, high LAP is associated with type 2 diabetes mellitus and high mortality rates due to heart failure in women with normal weight but with high cardiovascular risk. ${ }^{12,13}$

Recent studies in patients with PCOS suggest that LAP can be used to predict cardiovascular risk. ${ }^{3,11}$ The homeostatic model assessment index (HOMA-IR) is more commonly used for the diagnosis of insulin resistance in patients with PCOS, and is calculated on the basis of the insulin and fasting glycaemia levels. ${ }^{14}$ LAP showed greater accuracy than the HOMA-IR for the diagnosis of insulin resistance and glucose intolerance. ${ }^{13}$ It is worth mentioning that subclinical damage in the organs associated with glucose intolerance is present before the onset of diabetes. ${ }^{13}$ A patient with PCOS is considered a carrier of insulin resistance if LAP is $>34.5$. $^{15}$

Thus, the objective of this study was to evaluate whether PCOS patients with increased LAP have a higher prevalence of hirsutism (FGI $\geq 8$ ) than those with PCOS and normal LAP.

\section{Methods}

This was an observational, cross-sectional study of a secondary database with 410 patients at the Hyperandrogenism Outpatient Clinic of the Hospital das Clínicas of the Universidade Federal de Minas Gerais. We obtained the data during the care of patients with PCOS in that service from November 2009 to July 2014. The inclusion criteria were as follows: patients with PCOS (Rotterdam criteria) less than 40 years old; those who had completed at least 2 years after menarche at the time of evaluation; BMI $\geq 18.5 \mathrm{~kg} / \mathrm{m}^{2}$ and $<40 \mathrm{~kg} / \mathrm{m}^{2}$; patients who were not using medications that interfere with hormone and/or metabolic measurements for at least 3 months; and patients in whom metformin use had been suspended for 2 months. The exclusion criteria were patients with diabetes mellitus type 1 (or 2), androgensecreting tumors, Cushing syndrome, congenital adrenal hyperplasia, hyperprolactinemia, or untreated thyroid disorders. Patients with no data of abdominal circumference or triglyceride levels recorded in the database were excluded from the calculation of LAP. Finally, 263 patients were selected for the study.

The Rotterdam criteria were used for the diagnosis of PCOS, that is, the presence of two out of the following three findings: irregular menstrual cycles, clinical and/or laboratory hyperandrogenism, and presence of micro-polycystic ovaries upon US examination, after exclusion of other causes. All patients underwent medical assessment followed by measurement and recording of anthropometric data (weight, height, BMI, waist circumference, and blood pressure). They routinely underwent laboratory tests for measurements of the following: thyroid-stimulating hormone, follicle-stimulating hormone, prolactin, total testosterone, sex hormonebinding globulin, 17- $\alpha$-hydroxyprogesterone (follicular phase), glycohemoglobin A1c, and basal insulin and underwent lipid profiling and oral glucose tolerance tests. Other laboratory measurements were determined according to clinical criteria. LAP and the HOMA-IR were calculated using the data obtained, as previously described.

We divided the patients into two groups: the PCOS group with normal LAP $(<34.5)$ and the PCOS group with altered LAP ( $>34.5$ ) to compare the occurrence of hirsutism. We considered clinical hyperandrogenism in the presence of hirsutism (a score of FGI $\geq 8$ on physical examination) according to the modified criteria of Ferriman-Gallwey or the presence of moderate/severe acne (types 3 and 4) or androgenic alopecia.

In the second analysis, we divided patients per quartile, and the lower quartile (LAP < 29.0) was compared with the upper quartile (LAP > 79.5), by using the same cutoff point of the FGI.

In addition to the descriptive analyses (determination of frequencies, percentages, means, and standard deviation), 
74 Association between Lipid Accumulation Product and Hirsutism Oliveira et al.

Table 1 Clinical, hormonal, and metabolic profile by groups (normal $\times$ altered LAP)

\begin{tabular}{|l|l|l|l|}
\hline Parameters & Altered LAP & Normal LAP & P-value \\
\hline Age (years) & $33 \pm 6$ & $33 \pm 5$ & 0.638 \\
\hline Weight $(\mathrm{kg})$ & $87.7 \pm 16.7$ & $68.4 \pm 15.5$ & 0.0001 \\
\hline Height $(\mathrm{cm})$ & $1.62 \pm 0.07$ & $1.61 \pm 0.08$ & 0.552 \\
\hline BMI & $33.5 \pm 5.8$ & $26.2 \pm 4.9$ & 0.0001 \\
\hline AC $(\mathrm{cm})$ & $104.4 \pm 12.7$ & $85.8 \pm 10.9$ & 0.0001 \\
\hline HDL $(\mathrm{mg} / \mathrm{dL})^{2}$ & $43.5 \pm 9.5$ & $50.7 \pm 11.1$ & 0.0001 \\
\hline Fasting glucose $(\mathrm{mg} / \mathrm{dL})$ & $88.3 \pm 14$ & $85.2 \pm 14.9$ & 0.099 \\
\hline TGL $(\mathrm{mg} / \mathrm{dL})^{2}$ & $150.4 \pm 66.1$ & $74.1 \pm 25.2$ & 0.0001 \\
\hline Insulin $(\mu \mathrm{IU} / \mathrm{mL})$ & $17.8 \pm 19.5$ & $10.1 \pm 10.1$ & 0.001 \\
\hline HOMA-IR index ${ }^{2}$ & $3.9 \pm 4.8$ & $2.1 \pm 2.4$ & $1 \pm 1$ \\
\hline Number of MS criteria & $2 \pm 1$ & & 0.002 \\
\hline
\end{tabular}

Abbreviation: AC, abdominal circumference; BMI, body mass index; HDL, high-density lipoprotein; HOMA-IR, homeostatic model assessment of insulin resistance; LAP, lipid accumulation product; MS, metabolic syndrome; TGL, triglycerides.

we performed comparative statistical analyses. Among the comparative analyses, we used the Student's $t$-test to compare the means of the two independent groups and the chisquare test to compare categorical variables, in addition to the stratification of the data into quartiles, presented in a box-plot format. The SPSS Statistics for Windows ${ }^{\circledR}$ (IBM, Version 20.0. Armonk, NY) was used for the statistical analysis and the construction of the box-plots. Statistical significance was considered for a p-value $\leq 0.05$.

The authors declare no conflict of interest in conducting this study.

\section{Results}

Patients with PCOS and altered LAP had a lower mean value of high-density lipoprotein (HDL)-cholesterol (43.5 \pm 9.5 $\mathrm{mg} / \mathrm{dL}$ versus $50.7 \pm 11.1 \mathrm{mg} / \mathrm{dL} ; p=0.0001)$, a higher average BMI $(33.5 \pm 5.8$ versus $26.2 \pm 4.9 ; p=0.0001)$, and more criteria for the diagnosis of MS ( $2 \pm 1$ criteria versus $1 \pm 1$ criteria; $p=0.0001$ ) than patients with PCOS and normal LAP. - Table 1 summarizes the clinical, hormonal, and metabolic profiles in the two groups of patients (altered LAP versus normal LAP).

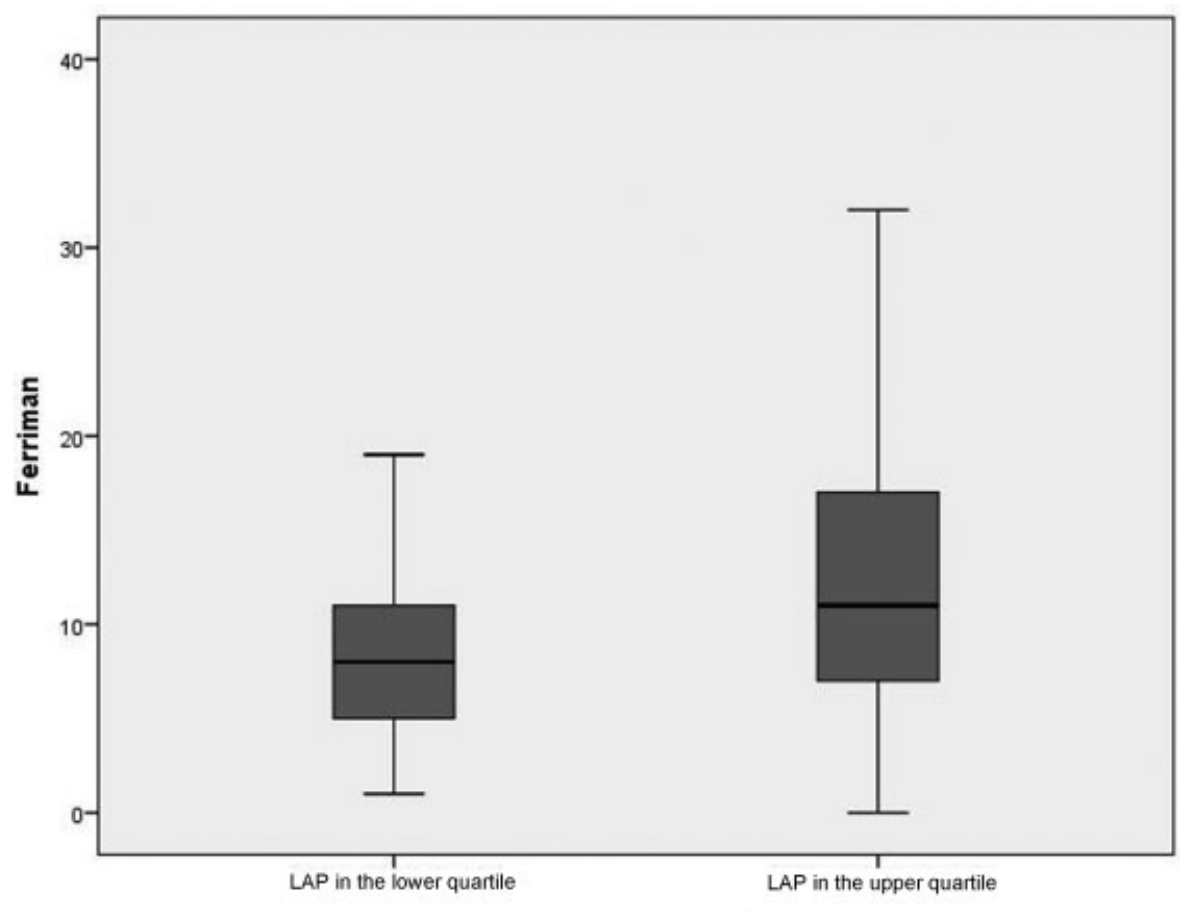

LAP in quartiles

Fig. 1 Box-plot comparing the Ferriman index with lipid accumulation product (LAP) in the upper and lower quartiles $(p=0.049)$. 
We observed that most patients analyzed (63.7\%; $n=177)$ had high LAP $(\geq 34.5)$. The same was observed in relation to the measures of the $\mathrm{FGI}$, i.e., most patients ( $n=154,58.6 \%)$ had hirsutism.

When analyzing the relation of the FGI by groups of LAP, we observed that in both groups of patients, there was a higher incidence of altered FGI $(\geq 8)$, with an incidence of $52.3 \%$ for the normal LAP group $(<34.5$ ) and $61.6 \%$ for the altered LAP group ( $\geq 34.5$ ), without a statistically significant difference (-Fig. 1).

The lower $(\mathrm{Q} 1=29.0)$ and upper $(\mathrm{Q} 3=79.5)$ quartiles showed significant differences in LAP $(p=0.04)$. This statistical relation was also confirmed using odds ratios that demonstrated that women with LAP $>79.5$ (upper quartile) had a 2-fold higher association with the altered FGI.

\section{Discussion}

Most patients in the study had high LAP $(\geq 34.5)$ and hirsutism. Patients with a normal FGI had LAP in the lower quartile (60.8\%). On the other hand, most patients with altered FGI had LAP in the upper quartile (56.8\%), indicating that hirsutism is associated with insulin resistance and cardiovascular risk, corroborating published data. ${ }^{12,13}$ In this context, it can be inferred that women with PCOS and hirsutism will have a greater chance of presenting an altered LAP index, indicating that this group of patients will present a higher risk of metabolic alterations. On the other hand, patients with the non-hyperandrogenic PCOS phenotype (normal FGI) present as a metabolically similar group to patients without PCOS. ${ }^{14}$ Patients with PCOS and hirsutism have been reported to have an increased risk of MS. ${ }^{8-10,16}$ The progressive accumulation of fat, mainly in the abdominal region, is characterized by an increase in insulin resistance. ${ }^{13}$ LAP reflects both the deposition of visceral fat and the increase of lipolytic activity within adipose tissue. ${ }^{13}$ The observation that patients with PCOS and hirsutism would also present an altered LAP index not only confirms the greater risk of MS but also allows for an early diagnosis of metabolic changes.

PCOS patients with an altered LAP index had lower mean HDL-cholesterol levels, higher mean BMI and HOMA-IR, and a greater chance of developing MS, reinforcing the finding previously described in the literature that LAP is a good predictor of cardiovascular risk. A recent meta-analysis showed that women with PCOS have lower levels of HDLcholesterol, regardless of BMI. ${ }^{17}$ Obesity has an estimated mean prevalence of $49 \%$ in PCOS patients, ${ }^{18}$ ranging from $12.5 \%$ to $100 \%, 2,3,19$ and its presence can aggravate metabolic and reproductive disorders associated with PCOS, ${ }^{19}$ including dyslipidemia and MS; the prevalence of MS varies according to the clinical phenotypes of PCOS. ${ }^{20}$

The groups evaluated in the study were relatively comparable and presented similar mean age and height. The hormonal and metabolic profile differed between groups, as expected, as the LAP is known to be associated with MS.

One of the main limitations of this study was that a secondary database was used as the data source obtained from the medical records of a single clinical center and the information contained therein was dependent on their correct completion.

The present study results showed that hirsutism correlates with an altered LAP index. This relation has clinical relevance because hirsutism, which is known to have a correlation with cardiovascular risk, is also related with an altered LAP index, indicating that patients with this condition have a higher risk of insulin resistance and cardiovascular disease. Hirsute women with PCOS should be perceived as having a potentially higher metabolic risk, a higher probability of insulin resistance, and other relevant comorbidities. The modified Ferriman-Gallwey scale could be a simple, low-cost, and useful way to infer an increased cardiovascular risk in patients with PCOS.

\section{Referências}

1 Azziz R, Carmina E, Dewailly D, et al; Androgen Excess Society. Positions statement: criteria for defining polycystic ovary syndrome as a predominantly hyperandrogenic syndrome: an Androgen Excess Society guideline. J Clin Endocrinol Metab 2006; 91(11):4237-4245

2 Rotterdam ESHRE/ASRM-Sponsored PCOS consensus workshop group. Revised 2003 consensus on diagnostic criteria and longterm health risks related to polycystic ovary syndrome (PCOS). Hum Reprod 2004;19(1):41-47

3 Bates GW, Legro RS. Longterm management of Polycystic Ovarian Syndrome (PCOS). Mol Cell Endocrinol 2013;373(1-2):91-97

4 March WA, Moore VM, Willson KJ, Phillips DI, Norman RJ, Davies MJ. The prevalence of polycystic ovary syndrome in a community sample assessed under contrasting diagnostic criteria. Hum Reprod 2010;25(2):544-551

5 Carmina E, Oberfield SE, Lobo RA. The diagnosis of polycystic ovary syndrome in adolescents. Am J Obstet Gynecol 2010; 203(3):201.e1-201.e5

6 Carmina E. Ovarian and adrenal hyperandrogenism. Ann N Y Acad Sci 2006;1092:130-137

7 Dalgard F, Svensson A, Holm JO, Sundby J. Self-reported skin morbidity in Oslo. Associations with sociodemographic factors among adults in a cross-sectional study. Br J Dermatol 2004; 151(2):452-457

8 Clark NM, Podolski AJ, Brooks ED, et al. Prevalence of polycystic ovary syndrome phenotypes using updated criteria for polycystic ovarian morphology: an assessment of over 100 consecutive women self-reporting features of polycystic ovary syndrome. Reprod Sci 2014;21(8):1034-1043

9 Rehme MFB, Pontes AG, Corrente JE, Franco JG Jr, Pontes A. [Contribution of hyperandrogenism to the development of metabolic syndrome in obese women with polycystic ovary syndrome]. Rev Bras Ginecol Obstet 2013;35(12):562-568

10 Silva RdoC, Pardini DP, Kater CE. Polycystic ovary syndrome, metabolic syndrome, cardiovascular risk and the role of insulin sensitizing agents. Arq Bras Endocrinol Metabol 2006;50(2): 281-290

11 Kahn HS. The "lipid accumulation product" performs better than the body mass index for recognizing cardiovascular risk: a population-based comparison. BMC Cardiovasc Disord 2005;5:26

12 Hosseinpanah F, Barzin M, Erfani H, Serahati S, Ramezani Tehrani F, Azizi F. Lipid accumulation product and insulin resistance in Iranian PCOS prevalence study. Clin Endocrinol (Oxf) 2014;81(1): 52-57

13 Malavazos AE, Cereda E, Ermetici F, et al. The "lipid accumulation product" is associated with 2-hour postload glucose outcomes in overweight/obese subjects with nondiabetic fasting glucose. Int J Endocrinol 2015;2015:ID836941 
76 Association between Lipid Accumulation Product and Hirsutism Oliveira et al.

14 Matthews DR, Hosker JP, Rudenski AS, Naylor BA, Treacher DF, Turner RC. Homeostasis model assessment: insulin resistance and beta-cell function from fasting plasma glucose and insulin concentrations in man. Diabetologia 1985;28(7):412-419

15 Wiltgen D, Benedetto IG, Mastella LS, Spritzer PM. Lipid accumulation product index: a reliable marker of cardiovascular risk in polycystic ovary syndrome. Hum Reprod 2009;24(7): 1726-1731

16 Brand JS, van der Tweel I, Grobbee DE, Emmelot-Vonk MH, van der Schouw YT. Testosterone, sex hormone-binding globulin and the metabolic syndrome: a systematic review and meta-analysis of observational studies. Int J Epidemiol 2011;40(1):189-207
17 Wild RA, Rizzo M, Clifton S, Carmina E. Lipid levels in polycystic ovary syndrome: systematic review and meta-analysis. Fertil Steril 2011;95(3):1073-9.e1, 11

18 Graff SK, Mário FM, Alves BC, Spritzer PM. Dietary glycemic index is associated with less favorable anthropometric and metabolic profiles in polycystic ovary syndrome women with different phenotypes. Fertil Steril 2013;100(4):1081-1088

19 Diamanti-Kandarakis E, Spritzer PM, Sir-Petermann T, Motta AB. Insulin resistance and polycystic ovary syndrome through life. Curr Pharm Des 2012;18(34):5569-5576

20 Yildiz BO, Bolour S, Woods K, Moore A, Azziz R. Visually scoring hirsutism. Hum Reprod Update 2010;16(1):51-64 